\title{
Dynamic Thiol/Disulfide Homeostasis and Oxidative DNA Damage in Adult Attention Deficit Hyperactivity Disorder
}

\author{
Faruk Kurhan', Hamit Hakan Alp ${ }^{2}$ \\ Departments of ${ }^{1}$ Psychiatry and ${ }^{2}$ Biochemistry, Faculty of Medicine, Van Yuzuncu Yil University, Van, Turkey
}

Objective: Insufficient number of oxidative stress studies have been conducted in patients with adult attention deficit hyperactivity disorder (ADHD). The objective of the current study is to examine the thiol/disulfide homeostasis as well as oxidative DNA damage levels in adult ADHD patients and to compare them with the results of healthy control subjects.

Methods: The study was inclusive of forty-nine patients who were diagnosed with adult ADHD, as well as thirty-three healthy volunteers to be used as the control group. The diagnosis of the patients was conducted according to the DSM-5 diagnostic criteria. Blood were stored under appropriate laboratory conditions. For the purpose of detecting the oxidative DNA damage level, an extraction of genomic DNA from leukocytes was carried out, and furthermore the levels of 8-hydroxy-2-deoxyguanosine (8-OHdG), apart from deoxyguanosine, were measured accordingly.

Results: Total thiol and the native thiol levels were observed to be statistically lower in adult ADHD patients as compared to the subjects in the healthy control group $(p=0.001)$. It was observed that the disulfide levels were higher in adult ADHD patients as compared to the healthy control subjects $(p=0.001)$. In addition, the levels of 8 -OHdG, which are considered as a marker for assessing DNA damage, were found to be significantly lower in the control group as compared to the adult ADHD patients $(p=0.001)$.

Conclusion: It was observed that the thiol/disulfide homeostasis had shifted towards disulfide, and 8-OHdG levels were increased in adult ADHD patients.

KEY WORDS: Adult ADHD; Thiol disulfide; Oxidative DNA damage.

\section{INTRODUCTION}

Attention Deficit Hyperactivity Disorder (ADHD) is a neurodevelopmental disorder that is generally diagnosed in childhood, which is also characterized by attention deficit, as well as hyperactivity, and impulsivity. Generally speaking, the academic achievements of individuals with ADHD are negatively affected, their cognitive functions are declined, they have difficulty in controlling their behavior, and in addition to experiencing emotional and behavioral problems, their social functionality is also affected [1].

Received: January 4, 2021 / Revised: February 2, 2021

Accepted: February 5, 2021

Address for correspondence: Faruk Kurhan

Department of Psychiatry, Faculty of Medicine, Van Yuzuncu Yil

University, Van 65100, Turkey

E-mail: fkurhan@hotmail.com

ORCID: https://orcid.org/0000-0003-3718-0458
ADHD is considered as one of the most frequently seen mental health disorders and affects $7.2 \%$ of children and adolescents, and $4 \%$ of the adult population all over the world [2]. Individuals diagnosed with ADHD in childhood also carry these diagnostic criteria into their adulthood [3]. Even if the symptoms disappear with aging, 50$70 \%$ of children diagnosed with $\mathrm{ADHD}$, retain diagnostic criteria of ADHD in their adulthood [4].

Studies have shown that ADHD may be inherited in 70$80 \%$ of the cases $[5,6]$. The use of tobacco products during pregnancy and environmental toxins, preterm birth, low birth weight, inadequate and imbalanced nutrition, and viral infections have been defined as risk factors for the development of ADHD [7-9].

The etiopathogenesis of ADHD has not been fully elucidated. However, it has been suggested that functional disorders related to the metabolism of neurotransmitters such as noradrenaline and dopamine, which

(c) This is an Open-Access article distributed under the terms of the Creative Commons Attribution Non-Commercial License (http://creativecommons.org/licenses/by-nc/4.0) which permits unrestricted non-commercial use, distribution, and reproduction in any medium, provided the original work is properly cited. 
are catecholamine derivatives found in the cerebral cortex, might play a role in its etiopathogenesis [10].

Several studies in the literature have demonstrated that oxidative stress levels significantly increase in ADHD. Recently higher blood levels of malondialdehyde have been reported in patients with ADHD [11], and furthermore, an increase in lipid peroxidation has been detected in patients with ADHD [12]. Additionally, increased xanthine oxidase levels have been noted in patients diagnosed with ADHD [13].

Free oxygen radicals are the natural by-products of metabolism. Under normal conditions, a balance exists between the production, and elimination rates of free oxygen radicals known as the oxidant/antioxidant balance [14]. Cell membrane damage, DNA damage, programmed cell death, and protein carboxylation are the types of irreversible damage induced by an excessive amount of free oxygen radicals [15]. Many organs and tissues are affected by free oxygen radicals, but brain tissue due to its dense lipid content, low antioxidant levels, and high oxygen consumption, is more susceptible to the harmful effects of these free radicals [16]. Of course, the body has some antioxidative defense mechanisms available to overcome these detrimental effects of free radicals. Thiols are one of the most important enzymes of antioxidant defense mechanisms [17].

Recently, studies have depicted that the thiol/disulfide homeostasis is disrupted in schizophrenia, autistic spectrum disorders, neurological disorders including migraine, epilepsy, and internal diseases such as diabetic nephropathy, which may be involved in the pathogenesis of many disorders [18-20].

Disulfide bonds are formed via oxidation of thiols. As the first observable change in protein oxidation, free oxygen radicals attack the thiol groups of sulfur-containing amino acids leading to oxidation [21].

The thiol group of the cysteine amino acid is highly susceptible to oxidative attack, and the thiol radical formed via different mechanisms from thiol groups induce formation of disulfide bonds in proteins [21]. The thiol/disulfide balance is vital for body detoxification, intracellular signal transduction, antioxidative defense, regulation of enzyme activity, as well as programmed cell death $[17,22]$.

Free oxygen radicals damage both intracellular and extracellular structures and disrupt genetic codes by inducing permanent changes in DNA [23]. As a marker of the oxidative stress, 8-hydroxy-2-deoxyguanosine (8-OHdG) suggestively impairs mitochondria through its oxidizing activity [24]. Normally, after oxidation, a number of cellular mechanisms repair the damaged DNA; and thus $8-\mathrm{OHdG}$, which is an indicator of mitochondrial oxidative damage, is removed from the body. Ultimately, endogenous $8-\mathrm{OHdG}$ may be detected in both the blood and urine, which can indicate the presence of damage to DNA. Hence, due to these findings, endogenous $8-\mathrm{OHdC}$ is considered as a biomarker for DNA damage in various diseases [25]. An increase in the level of 8-OHdG and resultant DNA damage have been detected in patients with ADHD compared to healthy volunteers [26]. However, when oxidative stress levels of newly diagnosed ADHD patients were compared, the similar levels of oxidative stress have been reported in both groups [27].

Levels of oxidative status in ADHD patients have been measured with various biomarkers. However, in our study, for the first time, thiol/disulfide homeostasis has been investigated and the levels of oxidative DNA damage in adult ADHD patients have been compared to the healthy group. As a relatively new marker of oxidative stress, thiol/disulfide homeostasis is disrupted in neuropsychiatric diseases. For the purposes of this study, we reviewed the relevant past literature, and for the first time in the literature, we have aimed to evaluate the thiol/disulfide balance as a marker of oxidative stress, and to compare the levels $8-\mathrm{OHdG}$, similar to many other diseases, ADHD negatively affects the oxidative processes in the organism

\section{METHODS}

This study was conducted at Psychiatry department of Medical Faculty at Van Yuzuncu Yil Universty between January 2020 and September 2020. The institutional ethical review board approved the study with reference number of 08 at 18.12.2019. The study participant were informed about the study and consent was obtained from all subjects.

Forty-nine patients, who were diagnosed with adult ADHD as per the defined Diagnostic and Statistical Manual of Mental Disorders 5th edition criteria by an experienced psychiatrist at Van Yuzuncu Yil University Psychiatry Clinic, were included in the work. The healthy group was comprised of 33 volunteers. 
Patients with metabolic, endocrine, and neurological disorders, diabetes mellitus, pregnancy, obesity, other psychiatric pathologies, mental retardation, psychosis, schizophrenia, mood disorders smokers, alcohol and substance addicts, cases with a history of antioxidant agent use, and those patients receiving electroconvulsive therapy were excluded from the current study.

Both groups were matched in condition of age, gender, smoking status, and other sociodemographic characteristics. Biochemical tests and inflammatory markers were investigated in all participants. All participants signed their informed consent forms.

\section{Detection of the Total Thiol Levels}

Briefly, $10 \mu \mathrm{l}$ of serum sample or standard, and $10 \mu \mathrm{l}$ of reagent one were mingled in a test tube. Following an incubation period of 100 seconds at room temperature, 110 $\mu$ of reagent two was added to the mix, while subsequently it was incubated for 200 seconds at room temperature. The initial absorbance was detected at a wavelength of $415 \mathrm{~nm}$. Then, $10 \mu$ l of reagent three was added to the mix and then it was incubated for 300 seconds at room temperature. The final absorbance was detected at 415 $\mathrm{nm}$. Total thiol levels were calculated based on the standard curve.

\section{Detection of Native Thiol Levels}

Ten $\mu \mathrm{l}$ of serum sample or standard and $100 \mu \mathrm{l}$ of reagent one were mixed in a test tube and incubated for 300 seconds at room temperature. Following the incubation period, the first absorbance was detected at a wavelength of $415 \mathrm{~nm}$. Then, $10 \mu \mathrm{l}$ of reagent two was added to the mix and subsequently incubated for another 300 seconds at room temperature. Following the incubation, the final absorbance was determined at $415 \mathrm{~nm}$ Native thiol levels were calculated based on the standard curve. Disulfide levels were calculated by subtracting the native thiol values from the total thiol values and dividing them by two. Disulfide/total thiol, disulfide/native thiol and native thiol/total thiol ratios were calculated and the results were given as percentages [28].

\section{Detection of Oxidative DNA Damage}

For the purposes of detecting the oxidative DNA damage, DNA was isolated from leukocytes and then $8-\mathrm{OHdG}$, as well as dG levels were measured. Initially, DNA was iso- lated from whole blood samples taken from patients and healthy subjects by using commercial DNA isolation kits (Nucleo Spin Blood DNA, RNA and Protein Preparation; Macherey-Nagel, Düren, Germany). Isolated DNA samples were hydrolyzed with formic acid, as previously described by Kaur and Halliwell $[29,30]$. The concentrations of 8-OHdG and dG of the hydrolyzed DNA samples were determined using the previously described high pressure liquid chromatography (HPLC) method with electrochemical detector (ECD) and variable wavelength detector [29]. Prior to analysis by HPLC, hydrolyzed DNA samples were dissolved in HPLC eluent in a final volume of $1 \mathrm{ml}$. A total of $20 \mu \mathrm{l}$ of final lysate was analyzed by HPLC-ECD. A reverse phase-C18 analytical column (250 mm, 4.6 mm, $4.0 \mu \mathrm{m}$; Phenomenex, Torrance, CA, USA) was used. The mobile phase contained $0.05 \mathrm{M}$ potassium phosphate buffer, pH 5.5 and acetonitrile (97:3, v/v) and the flow rate was $1 \mathrm{ml} / \mathrm{min}$. The $\mathrm{dG}$ concentration was monitored based on absorption at $245 \mathrm{~nm}$, and the $8-\mathrm{OHdG}$ level was determined based on the ECD reading (600 mV). The dG and 8-OHdG levels were measured using dG and 8-OHdG standards (Sigma Aldrich, St. Louis, $\mathrm{MO}$, USA); The 8-OHdG level was described as 8-OHdG/ $10^{6} \mathrm{dG}$.

\section{Statistical Analysis}

The results and the data from the study were assessed by utilizing the IBM SPSS 20 package program (IBM Co., Armonk, NY, USA). Shapiro-Wilks test was used to confirm the normality of distribution. Independent sample $t$ test and $\chi^{2}$ tests were utilized in order to compare the differences between both groups. Results were provided as mean \pm standard deviation. $p$ value of significance was determined as $p<0.05$.

\section{RESULTS}

Forty-nine adult patients with ADHD (mean age 26.4 \pm 4.11 years) and 33 healthy group (mean age 27.6 \pm 5.21 years) were included in this study. Both groups were matched in terms of age, gender status. Smokers, patients with a present or past history of alcohol and substance abuse were not included in the study. Height, weight, and body mass index of participants in both groups were measured, and the groups were matched according to these parameters. 
Table 1. Levels of total thiol, native thiol, disulfide, and $8-\mathrm{OHdG} / 10^{6} \mathrm{dG}$ in adult ADHD and control groups

\begin{tabular}{lccc}
\multicolumn{1}{c}{ Variable } & ADHD group $(\mathrm{n}=49)$ & Healthy control group $(\mathrm{n}=30)$ & $p$ value \\
\hline Total thiol $(\mu \mathrm{mol} / \mathrm{L})$ & $424.9 \pm 47.6^{*}$ & $549.9 \pm 44.1$ & 0.001 \\
Native thiol $(\mu \mathrm{mol} / \mathrm{L})$ & $386.6 \pm 49.7^{*}$ & $521.5 \pm 44.8$ & 0.001 \\
Disulfide $(\mu \mathrm{mol} / \mathrm{L})$ & $19.3 \pm 4.06^{*}$ & $13.7 \pm 4.91$ & 0.001 \\
Disulfide/native thiol $(\%)$ & $5.07 \pm 1.37^{*}$ & $2.66 \pm 1.01$ & 0.001 \\
Disulfide/total thiol $(\%)$ & $4.57 \pm 1.14^{*}$ & $2.51 \pm 0.89$ & 0.001 \\
Native thiol/total thiol $(\%)$ & $90.8 \pm 2.26^{*}$ & $94.6 \pm 1.78$ & 0.001 \\
8-OHdG/10 $\mathrm{dG}$ & $4.28 \pm 0.62^{*}$ & $2.48 \pm 0.63$ & 0.001 \\
\hline
\end{tabular}

Values are presented as mean \pm standard deviation.

8-OHdG, 8-hydroxy-2-deoxyguanosine; ADHD, attention deficit hyperactivity disorder.

${ }^{*} p$ : statistically significant compared to a healthy control group $(p=0.001)$.

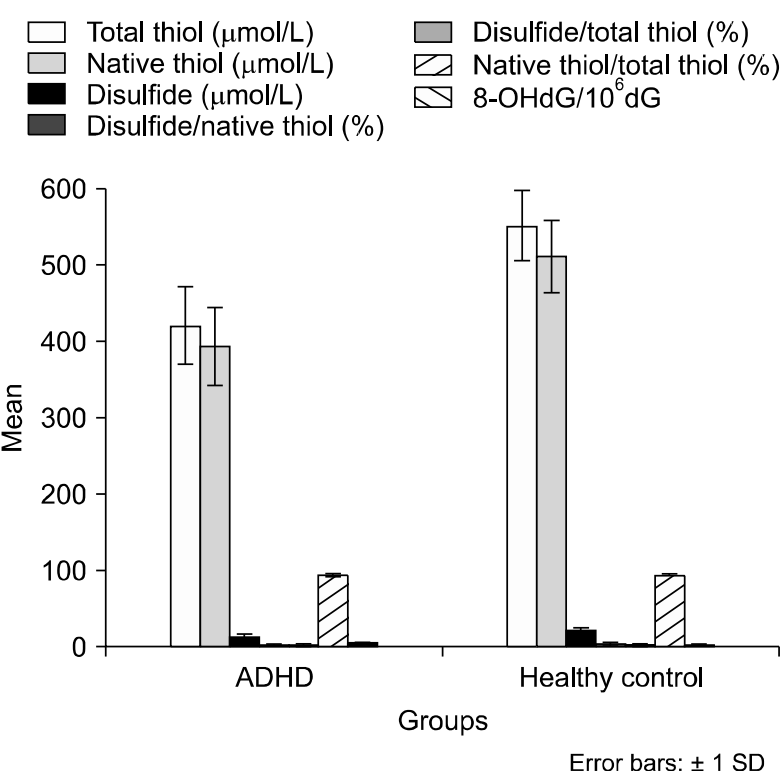

Fig. 1. The comparative chart of the levels of total thiol, native thiol, disulfide and $8-\mathrm{OHdG} / 10^{6} \mathrm{dG}$ in adult $\mathrm{ADHD}$ and control groups. 8-OHdG, 8-hydroxy-2-deoxyguanosine; ADHD, attention deficit hyperactivity disorder; SD, standard deviation.

The total thiol and native thiol levels were lower in adult ADHD patients compared to the healthy volunteers $(p=0.001)$. In addition, the disulfide levels were higher in adult ADHD patients $(p=0.001)$. Similarly, disulfide/total thiol and disulfide/native thiol levels were significantly higher in adult ADHD patients than those in the control group ( $p=0.001)$. On the other hand, the native/total thiol ratio was significantly higher in the control group ( $p=$ 0.001). The levels of $8-\mathrm{OHdG} / 10^{6} \mathrm{dG}$, a marker of oxidative DNA damage, were significantly higher in adult ADHD patients $(p=0.001)$. The results are presented in detail in Table 1 and Figure 1.

\section{DISCUSSION}

In our study, we examined the relationship of total thiol and native thiol levels in adult ADHD patients and it was determined that the total thiol and native thiol levels in adult ADHD patients were lower as compared to the control group. Furthermore, disulfide and disulfide/total thiol ratios were found to be higher in the control group. According to these results, it can be stated that the thiol/disulfide homeostasis has changed in favor of disulfide in adult ADHD patients. These results provide information about the oxidative status of adult ADHD patients. In other words, either the number of oxidative reactions has increased, or antioxidant components have decreased in adult patients with ADHD.

In a study reported a decline in total antioxidant status (TAS) levels in children with ADHD [31,32]. In another study demonstrated decreased glutathione peroxidase anti-oxidized enzyme activity, but increased catalase (CAT) enzyme activity in children with ADHD [11]. El Adham et al. [33] reported that serum levels of superoxide dismutase, glutathione-S-transferase, and CAT decreased in patients with ADHD. Ruchi et al. [34], stated that the activity of CAT enzyme decreased in saliva samples of ADHD patients. Oztop et al. [27] reported a lack of any difference between the patients with ADHD and healthy control subjects in terms of paraoxonase 1 and thiol antioxidant levels.

In a study reported increased plasma TAS levels in patients with ADHD [35]. On the contrary, In another study reported that the plasma TAS and thiol levels dropped in the ADHD group [36]. In addition, Nasim et al. [37] detected low serum CAT, glutathione (GSH), and TAS levels in patients with ADHD.

In the light of this information, we can conclude that 
when the oxidant-antioxidant balance shifts towards the oxidative side, then as a result, the antioxidant defense system weakens, or the number of oxidative reactions increases. Various assumption have been proposed to describe the etiology of oxidative damage in brain tissue. An interaction between the hypothalamic-pituitary-adrenal (HPA) axis, sympathoadrenal-medullary systems, and oxidative stress has been proposed [38]. An alternative explanation of the mechanisms underlying oxidative stress is that neurotransmitters such as noradrenaline and dopamine, which are catecholamine derivatives, may induce the activation of the sympathetic system via the HPA axis. These activations trigger the release of corticosterone and hormones in the adrenal medulla [39].

Reactive oxygen species (ROS) target primarily the - $\mathrm{SH}$ group of the cysteine contained in the structure of proteins. As ROS attack these protein structures, $-\mathrm{SH}$ is oxidized to disulfide, and then the protein may lose its function. Thiol-containing compounds such as GSH are important components of the organism's antioxidant defense system. In addition, they are important for apoptosis as well as the stabilization of proteins.

Assessment of the shift in the thiol/disulfide balance can present information concerning the oxidative state. Ates et al. [40] in their study have shown that in diabetic patients, the thiol/disulfide homeostasis is impaired, and Altıparmak et al. [41] have demonstrated that this balance is disrupted in favor of disulfide in patients with coronary artery disease. Erzin et al. [28,42] demonstrated that the lower serum native thiol levels in bipolar patients who were in remission, and higher levels of disulfide in patients with bipolar disorder and unipolar depression. A study by Unal et al. [43] researched the thiol/disulfide homeostasis in patients with schizophrenia and they demonstrated that the disulfide levels were significantly higher, but native and total thiol levels were significantly lower in schizophrenic patients.

The findings of this research have suggested that the thi$\mathrm{ol} /$ disulfide balance is severely disrupted in adult ADHD patients and larger studies should be conducted to measure the difference between untreated patients, control subjects, as well as those patients that are receiving regular or irregular treatment for ADHD. Adult patients and children with ADHD should be compared in terms of oxidant/antioxidant status and any difference between the adults who were diagnosed with ADHD in childhood or adulthood. Further studies can evaluate this question and our study has the potential to provide important information.

Mechanisms that regulate oxidative stress such as thiol-disulfide homeostasis are associated with various biochemical processes and are not specific to a pathology. Therefore, the result found in patients with adult ADHD is not a specific result; it indicates that the oxidation process created by ADHD in cellular processes is higher than in controls. Rather than being a biomarker to be used in diagnosis, it necessitates the consideration of oxidative processes in treatment management.

This study has also shown that the $8-\mathrm{OHdG}$ levels, which are indicators of oxidative DNA damage, increases in adult ADHD patients. Unlike previous studies, we did not detect 8-OHdG levels in serum, plasma, or urine; but in DNA lesions in order to assess the DNA damage in patients with adult ADHD by using a more sensitive HPLC method. If the base modifications caused by the attack of ROS are not corrected by DNA repair genes, then they induce mutations in DNA. Subsequently, the proteins encoded by these genes become nonfunctional, which may lead to serious complications. A body of evidence has shown that the structure of lipids and proteins in cell membranes and DNA can be irreversibly damaged. DNA in both nuclei and mitochondria are major indicators of 8-OHdG damage, which is constantly triggered by free oxygen radicals [23].

Oztop et al. [27] reported that in the patient group there was a decrease in plasma $8-\mathrm{OHdG}$ levels in the group comprised of the patients as compared to the control group. In the study by Simsek et al. [44], it was shown that 8-OHdG levels were not different between the ADHD patients and the control group. Verlaet et al. [45] found that the urine levels of $8-\mathrm{OHdG}$ had elevated in $\mathrm{ADHD}$ patients. Post-mortem examinations have depicted that the increase in the levels of 8-OHdG in cranial tissue samples and bodily fluids are associated with many degenerative diseases and carcinogenesis [46]. The presence of 8-OHdG has been detected as an indicator of oxidative DNA damage in post-mortem studies that have been conducted with deceased patients with the diagnosis of psychiatric illnesses [46]. A tenfold increase in the serum level of 8-OhdG in the hippocampus region has been demonstrated in post-mortem studies of schizophrenics [47]. High levels of serum 8-OHdG have also been reported in patients with major depression [48]. In addition, it has 
been reported that patients who experienced recurrent depressive episodes have experienced them more severely due to oxidative DNA damage than patients with a history of only a single episode [49].

In our review of literature data, we have seen that different 8-OHdG levels have been reported. These discrepancies among studies may be related to the variations in the types of samples, the sampling methods, patient profiles, and the experimental methods used. In our study, we did not measure the urinary or plasma levels of $8-\mathrm{OHdG}$, but rather we measured the $8-\mathrm{OHdG}$ levels using a more sensitive HPCL method.

Limitations of the study: Although we tried to homogenize the groups, since each group consisted of a scarce number of patients, and a large spectrum of drugs were used by the patients, we were not able to divide the groups into subgroups. As the OCD group consisted of a small number of patients, it was not possible to classify the patients according to the severity of the disease. In addition, we were unable to eliminate factors that may affect levels of oxidative stress such as family medical histories, diet, sleep patterns, exercise status, and working conditions of the participants. Thus, as suggested above, further studies are recommended in this field that take into account the limitations that we have depicted above. This way, our results can be strengthened, and more data can be obtained for future medical purposes. Especially studies with a higher number of participants are recommended for the future.

We have shown that the thiol/disulfide balance changes toward oxidative side in ADHD patients. Furthermore, as marker of DNA damage, the levels of 8-OHdG were observed to be quite high in ADHD patients. The regulation of oxidative stress balance in adult $A D H D$ patients will be helpful in the treatment of ADHD and also in decreasing morbidity. Based on these results, we can suggest that thi$\mathrm{ol} /$ disulfide balance is severely impaired in adult ADHD patients and hence larger-scale studies should be conducted to ascertain the difference between untreated patients, as well as those patients who received regular or irregular treatment for $\mathrm{ADHD}$ and control groups. In addition, adult ADHD patients who were diagnosed a long time ago and recently should be compared. The adult ADHD patients should be examined in terms of disease duration, treatment status, and the levels of oxidative stress.

\section{Acknowledgments}

The authors would like to thank that work was funding by the Scientific Research Projects Coordination Unit of Yüzüncü Yil Universty (THD-2020-8890).

\section{Conflicts of Interest}

No potential conflict of interest relevant to this article was reported.

\section{Author Contributions}

Conceptualization: Faruk Kurhan, Hamit Hakan Alp. Data acquisition: Faruk Kurhan, Hamit Hakan Alp. Formal analysis: Faruk Kurhan, Hamit Hakan Alp. Supervision: Faruk Kurhan. Writing-original draft: Faruk kurhan. Writing - review \& editing: Faruk Kurhan. All authors interpreted the results and helped to revise the manuscript.

\section{ORCID}

Faruk Kurhan https://orcid.org/0000-0003-3718-0458

Hamit Hakan Alp https://orcid.org/0000-0002-9202-4944

\section{REFERENCES}

1. American Psychiatric Association. Diagnostic and statistical manual of mental disorders: DSM-5. Arlington:American Psychiatric Pub.;2013.

2. Wolraich ML, Hagan JF Jr, Allan C, Chan E, Davison D, Earls $\mathrm{M}$, et al. Clinical practice guideline for the diagnosis, evaluation, and treatment of attention-deficit/hyperactivity disorder in children and adolescents. Pediatrics 2019;144:e20192528.

3. Barkley RA, Fischer M, Smallish L, Fletcher K. The persistence of attention-deficit/hyperactivity disorder into young adulthood as a function of reporting source and definition of disorder. J Abnorm Psychol 2002;111:279-289.

4. Meza JI, Monroy M, Ma R, Mendoza-Denton R. Stigma and attention-deficit/hyperactivity disorder: negative perceptions and anger emotional reactions mediate the link between active symptoms and social distance. Atten Defic Hyperact Disord 2019;11:373-382.

5. Smalley SL, McGough JJ, Del'Homme M, NewDelman J, Gordon E, Kim T, et al. Familial clustering of symptoms and disruptive behaviors in multiplex families with attention-deficithyperactivity disorder. J Am Acad Child Adolesc Psychiatry 2000;39:1135-1143.

6. Barkley RA. Attention-deficit hyperactivity disorder: a handbook for diagnosis and treatment. New York:Guilford Publications;2014.

7. Nigg JT, Elmore AL, Natarajan N, Friderici KH, Nikolas MA. Variation in an iron metabolism gene moderates the associa- 
tion between blood lead levels and attention-deficit/hyperactivity disorder in children. Psychol Sci 2016;27:257-269.

8. Nigg JT, Breslau N. Prenatal smoking exposure, low birth weight, and disruptive behavior disorders. I Am Acad Child AdolesC Psychiatry 2007;46:362-369.

9. Knopik VS, Sparrow EP, Madden PA, Bucholz KK, Hudziak JJ, Reich W, et al. Contributions of parental alcoholism, prenatal substance exposure, and genetic transmission to child ADHD risk: a female twin study. Psychol Med 2005;35:625-635.

10. Del Campo N, Chamberlain SR, Sahakian BJ, Robbins TW. The roles of dopamine and noradrenaline in the pathophysiology and treatment of attention-deficit/hyperactivity disorder. Biol Psychiatry 2011;69:e145-e157.

11. Ceylan M, Sener S, Bayraktar AC, Kavutcu M. Oxidative imbalance in child and adolescent patients with attention-deficit/hyperactivity disorder. Prog Neuropsychopharmacol Biol Psychiatry 2010;34:1491-1494.

12. Kawatani M, Tsukahara $\mathrm{H}$, Mayumi M. Evaluation of oxidative stress status in children with pervasive developmental disorder and attention deficit hyperactivity disorder using urinary-specific biomarkers. Redox Rep 2011;16:45-46.

13. Ceylan MF, Sener S, Bayraktar AC, Kavutcu M. Changes in oxidative stress and cellular immunity serum markers in attention-deficithyperactivity disorder. Psychiatry Clin Neurosci 2012;66:220-226.

14. Altan N, Dinçel A, Koca C. Diabetes mellitus and oxidative stress. Turk J Biochem 2006;31:51-56.

15. Maes M, Kubera M, Leunis JC, Berk M, Geffard M, Bosmans E. In depression, bacterial translocation may drive inflammatory responses, oxidative and nitrosative stress (O\&NS), and autoimmune responses directed against O\&NS-damaged neoepitopes. Acta Psychiatr Scand 2013;127:344-354.

16. Ng F, Berk M, Dean O, Bush Al. Oxidative stress in psychiatric disorders: evidence base and therapeutic implications. Int J Neuropsychopharmacol 2008;11:851-876.

17. Circu ML, Aw TY. Reactive oxygen species, cellular redox systems, and apoptosis. Free Radic Biol Med 2010;48:749-762.

18. Milenkovic D, Jude B, Morand C. miRNA as molecular target of polyphenols underlying their biological effects. Free Radic Biol Med 2013;64:40-51.

19. Topcuoglu C, Bakirhan A, Yilmaz FM, Neselioglu S, Erel O, Sahiner SY. Thiol/disulfide homeostasis in untreated schizophrenia patients. Psychiatry Res 2017;251:212-216.

20. Eren MA, Koyuncu İ, İncebıyı H, Karakaş H, Erel Ö, Sabuncu T. The evaluation of thiol/disulphide homeostasis in diabetic nephropathy. Diabetes Res Clin Pract 2019;148:249-253.

21. Kayalı R, Çakatay U. Protein oksidasyonunun ana mekanizmalari. Cerrahpasa Med J 2004;35:83-89.

22. Biswas S, Chida AS, Rahman I. Redox modifications of protein-thiols: emerging roles in cell signaling. Biochem Pharmacol 2006; 71:551-564.

23. Valko M, Rhodes CJ, Moncol J, Izakovic M, Mazur M. Free radicals, metals and antioxidants in oxidative stress-induced cancer. Chem Biol Interact 2006;160:1-40.

24. Long JD, Matson WR, Juhl AR, Leavitt BR, Paulsen JS; PREDICT-HD Investigators and Coordinators of the Huntington Study Group. 8OHdG as a marker for Huntington disease progression. Neurobiol Dis 2012;46:625-634.

25. Yokuş B, Çakir DÜ. Biomarker of invivo oxidative DNA damage; 8-hydroxy-2'-deoxyguanosine. Turkiye Klinikleri Tip Bilimleri Dergisi 2002;22:535-543.

26. Alpak G, Selek S, Bulut M, Bulbul F, Unal A, Virit O, et al. High catalase and low thiol levels in adult-ADHD patients. Bull Clin Psychopharmacol 2014;24:128-134.

27. Oztop D, Altun H, Baskol G, Ozsoy S. Oxidative stress in children with attention deficit hyperactivity disorder. Clin Biochem 2012:45:745-748.

28. Erzin G, Kotan VO, Topçuoğlu C, Özkaya G, Erel Ö, Yüksel $\mathrm{RN}$, et al. Thiol/disulphide homeostasis in bipolar disorder. Psychiatry Res 2018;261:237-242.

29. Kaur H, Halliwell B. Measurement of oxidized and methylated DNA bases by HPLC with electrochemical detection. Biochem J 1996;318(Pt 1):21-23.

30. Shigenaga MK, Aboujaoude EN, Chen Q, Ames BN. Assays of oxidative DNA damage biomarkers 8-oxo-2'-deoxyguanosine and 8-oxoguanine in nuclear DNA and biological fluids by high-performance liquid chromatography with electrochemical detection. Methods Enzymol 1994;234:16-33.

31. Chovanová Z, Muchová J, Sivonová $M$, Dvoráková $M$, Zitnanová I, Waczulíková I, et al. Effect of polyphenolic extract, Pycnogenol, on the level of 8-oxoguanine in children suffering from attention deficit/hyperactivity disorder. Free Radic Res 2006;40:1003-1010.

32. Dvoráková M, Sivonová M, Trebatická J, Skodácek I, Waczuliková I, Muchová J, et al. The effect of polyphenolic extract from pine bark, Pycnogenol on the level of g/utathione in children suffering from attention deficit hyperactivity disorder ( $A D H D$ ). Redox Rep 2006;11:163-172.

33. El Adham EK, Hassan Al, El Aziz El-Mahdy A. Nutiritional and metabolic disturbances in attention deficit hyperactivity disease. Res J Med Med Sci 2011;6:10-16.

34. Ruchi K, Kumar A, Sunil G, Bashir A, Prabhat S. Antioxidant activity in children with $A D H D$ - a comparison in untreated and treated subjects with normal children. IIUMMed J Malays 2011;10:31-35.

35. Selek S, Bulut M, Ocak AR, Kalenderoğlu A, Savaş HA. Evaluation of total oxidative status in adult attention deficit hyperactivity disorder and its diagnostic implications. I Psychiatr Res 2012;46:451-455.

36. Guney E, Cetin FH, Alisik M, Tunca H, Tas Torun Y, Iseri E, et al. Attention Deficit Hyperactivity Disorder and oxidative stress: a short term follow up study. Psychiatry Res 2015;229: 310-317.

37. Nasim S, Naeini AA, Najafi M, Ghazvini M, Hassanzadeh A. Relationship between antioxidant status and attention deficit hyperactivity disorder among children. Int J Prev Med 2019; 
10:41.

38. Haddad JJ, Saadé NE, Safieh-Garabedian B. Cytokines and neuro-immune-endocrine interactions: a role for the hypothalamic-pituitary-adrenal revolving axis. I Neuroimmunol 2002;133:1-19.

39. Terawaki H, Terada T, Ogura M, Era S, Hosoya T. The elevation of oxidative stress after the great East Japan earthquake. Clin Exp Nephrol 2012;16:816-817.

40. Ates I, Kaplan M, Yuksel M, Mese D, Alisik M, Erel Ö, et al. Determination of thiol/disulphide homeostasis in type 1 diabetes mellitus and the factors associated with thiol oxidation. Endocrine 2016;51:47-51.

41. Altıparmak IH, Erkuş ME, Sezen H, Demirbag R, Gunebakmaz $\mathrm{O}$, Kaya Z, et al. The relation of serum thiol levels and thiol/disulphide homeostasis with the severity of coronary artery disease. Kardiol Pol 2016;74:1346-1353.

42. Erzin G, Özkaya G, Topçuoğlu C, Yüksel RN, Erel Ö, Yurt EF, et al. Thiol/disulfide homeostasis in bipolar and unipolar depression. Clin Psychopharmacol Neurosci 2020;18:395-401.

43. Ünal K, Erzin G, Yüksel RN, Alisik M, Erel Ö. Thiol/disulphide homeostasis in schizophrenia patients with positive symptoms. Nord J Psychiatry 2018;72:281-284.

44. Simsek S, Gencoglan S, Ozaner S, Kaplan I, Kaya MC. Antioxidant status and DNA damage in children with attention deficit hyperactivity disorder with or without comorbid disruptive behavioral disorders. Bull Clin Psychopharmacol 2016;26:119125.

45. Verlaet AAJ, Breynaert A, Ceulemans B, De Bruyne T, Fransen $\mathrm{E}$, Pieters $\mathrm{L}$, et al. Oxidative stress and immune aberrancies in attention-deficit/hyperactivity disorder (ADHD): a case-control comparison. Eur Child Adolesc Psychiatry 2019;28:719729.

46. Che Y, Wang JF, Shao L, Young T. Oxidative damage to RNA but not DNA in the hippocampus of patients with major mental illness. J Psychiatry Neurosci 2010;35:296-302.

47. Nishioka N, Arnold SE. Evidence for oxidative DNA damage in the hippocampus of elderly patients with chronic schizophrenia. Am J Geriatr Psychiatry 2004;12:167-175.

48. Forlenza MJ, Miller GE. Increased serum levels of 8-hydroxy-2'-deoxyguanosine in clinical depression. Psychosom Med 2006;68:1-7.

49. Ceprnja M, Derek L, Unić A, Blazev M, Fistonić M, KozarićKovacić D, et al. Oxidative stress markers in patients with post-traumatic stress disorder. Coll Antropol 2011;35:11551160. 